\title{
A Brief Introduction to Building Information Modeling (BIM) and its interoperability with TRNSYS
}

\author{
A. Boukara ${ }^{a} \&$ A. Naamane ${ }^{b}$ \\ a École Nationale Supérieure d'Architecture de Marseille, L'unité de recherche PROJECT[s] \\ email: abdelaziz.boukara@marseille.archi.fr \\ ${ }^{\mathrm{b}}$ Aix Marseille Université, CNRS, ENSAM, Université de Toulon, LSIS UMR 7296, 13397, \\ Marseille France, email: aziz.naamane@lsis.org
}

\begin{abstract}
Hand-drafted print, sketching and hand modeling were the standard for building designs before the advent of computer aided design (CAD) systems. Nowadays CAD systems are better understood, their adoption increased until the 2D, 3D CAD system and the virtual reality system have become the norm. Their natural evolution has given rise to a new and more complex generation of building design tools known as building information modeling, or BIM.
\end{abstract}

There is insufficient clarity about what BIM is, although this is improving, and there is much shared understanding. There is agreement that BIM is not just software. BIM is not just CAD, or geometric data. BIM is a collaboratively generated and maintained data rich information source for the life of the design process and beyond. In this paper, we present briefly the greatest value derived from BIM in the use and maintenance of buildings and the use of TRNSYS with BIM.

\section{Nomenclature -}

$\begin{array}{ll}\text { BIM } & \text { Building Information Modeling } \\ \text { CAD } & \text { Computer Assisted Design } \\ \text { MEP } & \text { Mechanical, Electrical \& Plumbing } \\ \text { TRNSYS } & \text { Transient Simulation Program }\end{array}$

\section{INTRODUCTION}

Wikipedia defines Building Information Modeling (BIM) as the process of generating and managing building data during its life cycle using threedimensional, real-time, dynamic building modeling software to decrease wasted time and resources in building design and construction. This process produces the building information model (also abbreviated BIM), which encompasses building geometry, spatial relationships, geographic information, and quantities and properties of building components, including the life-cycle processes of construction and facility operation. Building
Information Modeling (BIM, the process) began as a common name for a variety of activities in objectoriented computer-aided design (CAD) that support the representation of building elements in terms of their 3D geometric and non-geometric (functional) attributes and relationships[2].

\section{WHAT IS BIM?}

BIM is an intelligent model-based process that provides insight to help you plan, design, construct, and manage buildings and infrastructure. So BIM goes further than traditional CAD drawings by providing intelligence to individual building components (e.g. windows, walls or chillers) as well as providing system- and building-wide information and awareness (system flows or building loads) in addition to simple spatial relationships.

The BIM process involves participants from the entire project life cycle (architect, engineer, contractor, owner, facilities management, etc.) who all contribute and communicate with BIM designers, who are asked to provide more accurate energy modelling data. It is important to not consider and think that BIM is a software; BIM should be considered as the process of creating and using digital models for design, construction and/or operations of building projects. These models combine intelligent 2D and 3D objects used to define a building design, along with external factors, such as geographic location and local conditions, into a virtual building database that provides a single, integrated source for all information associated with that building's design.

The "intelligence" attributed to the objects includes parametrically-defined graphical and non-graphical information, giving the architects, MEP engineers, and contractors the ability to represent geometric and functional relationships between building elements. This information feeds an integrated database, which in turn feeds all design documents and schedules for 
the building project. When a change is made to the building model, all graphical views (plan, elevation, detail, and other construction drawings), as well as non-graphical views, such as the design documents and schedules, automatically reflect the change. Therefore, the main advantages of BIM are:

\section{A. Improved information flow}

Because a digital model represents a unified description of a building, it can significantly improve the flow of information in every stage of the design, construction, and life cycle of a building The digital model can be accessed by the architects, MEP engineers, contractors, facilities managers, and owners at different phases in the building life cycle to add, extract, or modify information in support of their role. A clear vision of the project is maintained to promote informed decisions, reduce errors, and improve productivity[5].

\section{B. Better design visualization}

The ability to predict how occupants, visitors, and neighbors will react to and interact with a building is a crucial part of the design process for architects and engineers. However, the virtual building model created during the BIM process also provides an important benefit in helping MEP engineers optimize the layout of the HVAC system within the space constraints of the building design [2]. Whether placing an air handler in a mechanical room, or routing piping or ductwork, the ability to virtually build the HVAC system and visually examine it in $3 D$ can provide added assurance that all components will fit when construction begins [3].

\section{Improved cost estimating}

BIM can simplify and help provide better cost estimates because of the depth and precision of the information it provides. The relative ease with which material and assembly quantities can be extracted from the model can increase the speed and accuracy of estimates, providing a better gauge of the impact of design changes so that budget concerns can be dealt with proactively.

\section{Improved energy analysis}

Here again, BIM can simplify and improve the accuracy of energy analysis because the data required to perform such analysis is resident in the digital building model [4].

\section{E. Reduced construction costs}

Clash detection can be used long before construction begins to show where parts of the design occupy the same space. This can reduce or eliminate the need for changes in the field during construction. BIM models can also be used to help prefabricate building components, such as duct or pipe runs, with confidence. This can save in costs associated with assembly and installation.

\section{F. Building history}

As a building passes through design, construction, and into occupancy, the digital model can serve as an important information library for owners and service contractors. For example, if a building component fails, the building information model can be used to identify its location, manufacturer, model number, performance specifications, and other pertinent data to most efficiently repair or replace that component. If a portion of the building is being remodeled, the building information model can be used to identify concealed components, such as piping, ductwork, and electrical equipment to promote informed decisions on the remodel design[6].

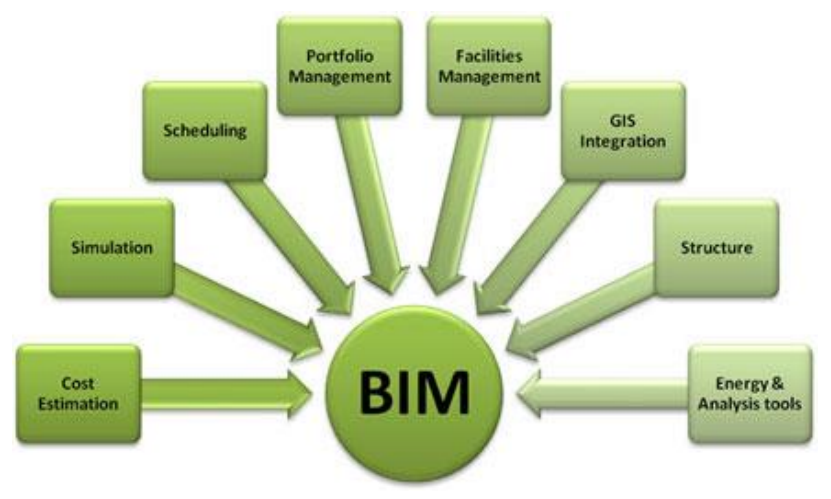

Fig .1 Bim environment

\section{TRYNSYS AND BIM}

TRNSYS is a complete, modular, and expansible simulation environment for the transient simulation of thermal systems including multi-zone buildings [1], [8]. It is used by engineers and researchers around the world to validate new energy concepts, from simple solar domestic hot water systems to the design and simulation of buildings and their equipment, including control strategies, occupant behavior, alternative energy systems (wind, solar, photovoltaic, hydrogen systems), etc. 
One of the key factors in TRNSYS' success over the last 25 years is its open, modularstructure. The source code of the kernel as well as the component models is delivered to theusers. This simplifies extending existing models to make them fit the user's specific needs. No single computer application can support all of the tasks associated with building design and production. Interoperability depicts the need to pass data and knowledge between applications, allowing multiple types of experts and applications to contribute to the work at hand. Interoperability has traditionally relied on file -based exchange formats, such as DXF (Drawing eXchange Format, or another type of date as dwg and more) and IGES that exchange only geometry. In this part, we present how TRNSYS is used in BIM Framework.

\section{STUDY CASE: DYNAMIC THERMAL SIMULATION OF A BUILDING}

The project consists of 8 buildings as shown on the below ground plane.

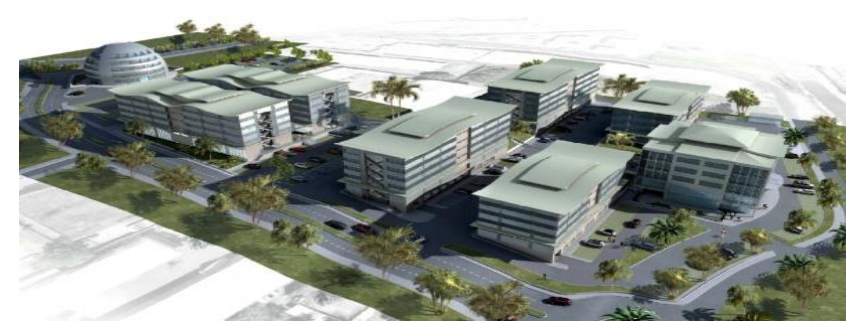

The study will focus on building $E$. The objective is to analyze the thermal behaviour of the building and evaluate the impact of technical or architectural choices in order to justify the proposed solution. In this case, the standard building, initially defined without insulation on the external envelop was modified by taking into account the glazing surface in the building.

The simple glazing was changed to a double glazing layer incorporated with Argon. A dynamic thermal simulation with TRNSYS software was conducted. The simulation results are presented as output data, hour by hour: temperature, moisture, powers of air conditioning, energy consumption, and so forth, related to the building behaviour and its occupants.

The different steps carried out in the simulation are the following:

\section{A. Step 1}

The building is obtained on a graphical format compatible with sketch up environment

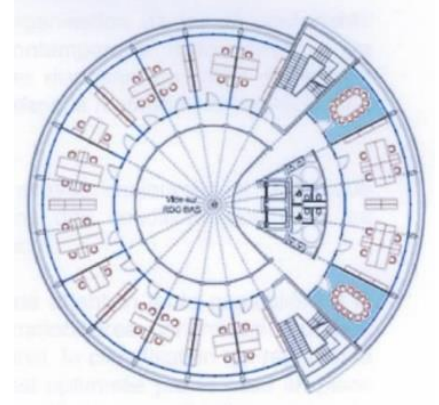

Fig .2 CAD Format

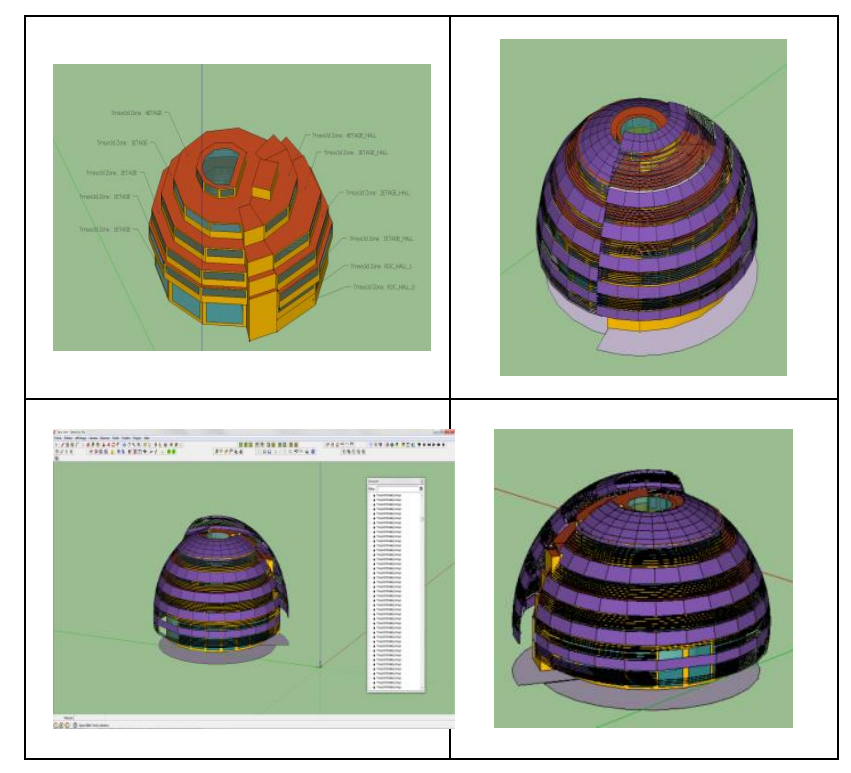

Fig .3 Sketchup view using TRNS3D (Open Studio) plugin

\section{B. Step 2}

Thermophysical properties are affected to the external envelop

\begin{tabular}{|l|l|c|c|}
\hline \multicolumn{1}{|c|}{ Type de paroi } & \multicolumn{1}{|c|}{ Composition } & $\begin{array}{c}\text { Coefficient U } \\
\text { En W/m².K }\end{array}$ & $\begin{array}{c}\text { Facteur } \\
\text { solaire }\end{array}$ \\
\hline Plancher bas & Dalle béton & 0.58 & $\cdot$ \\
\hline Plancher sous combles & Dalle béton & 0.95 & \\
\hline Vitrages & Vitrage simple clair & $U g=5.8$ & $82 \%$ \\
\hline Murs extérieurs & Béton & 3.94 & - \\
\hline Cloisons intérieures & Plattre/Laine de verre $5 \mathrm{~cm}$ & 0.67 & $\cdot$ \\
\hline Terrasse & Dalle béton & 0.952 & \\
\hline
\end{tabular}

Once the operation has been completed the file is saved in an appropriate format idf. This enables to make the connection between Sketchup and TRNSYS. 


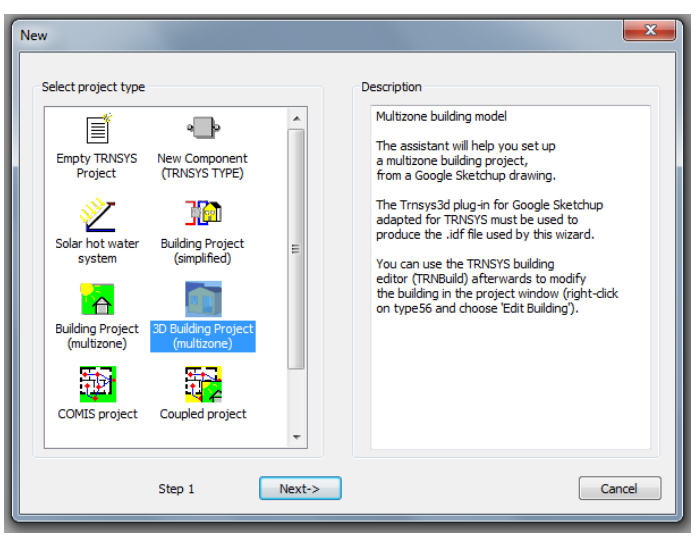

Fig .4 Opening the idf format on simulation Studio

TRNsys is loaded with features that allow making the link between the geometric modeling and thermal modeling, so it minimizes the time and the loss of the data; this interface returns fully under the BIM approach.The tool that is used to set all the thermophysical, properties and in this case the different consumption and internal inputs as a function of the scenarri is TRNbuild. The latter allows thermophysical modifications at the level of the envelope and its properties.

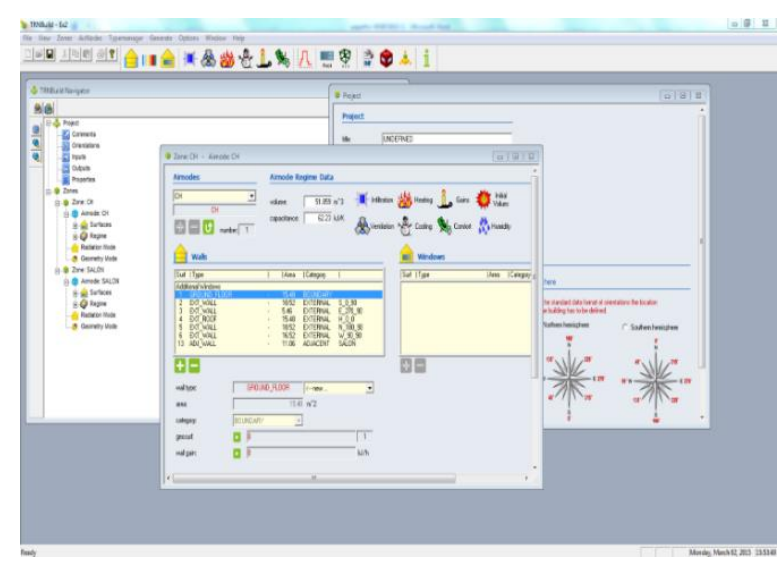

Fig .5 TRNbuild environment

Heat transfer calculations are made in TRNbuild and forwarded to the studio simulation environment in which the building is being updated (data).

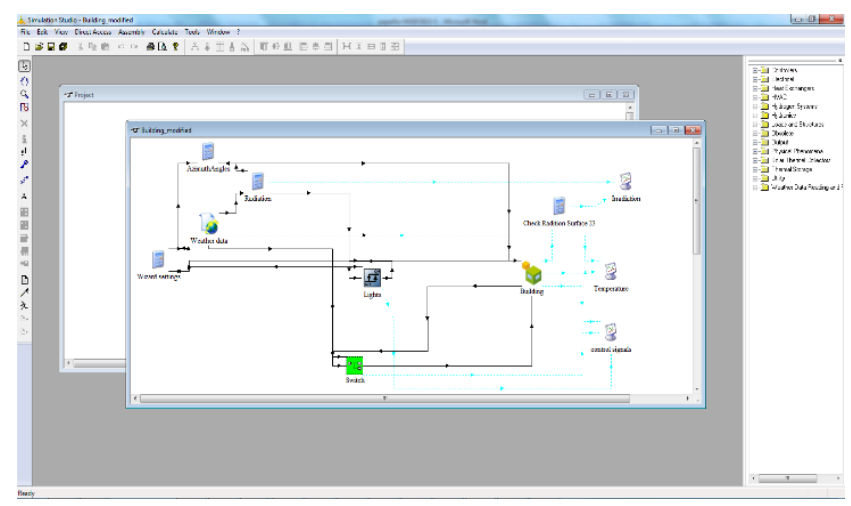

Fig .6 Managing the project on Open studio environment

\section{SIMULATION RESULTS}

After making several parametric simulations, we obtained the following results concerning the comfort temperature and energy consumption (summer comfort) parameters.

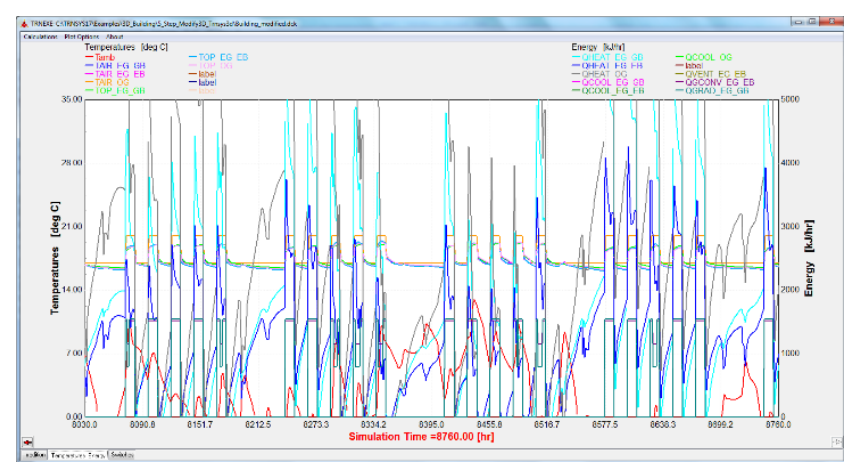

Fig .7 Simulation results (type 65 , online plotter)
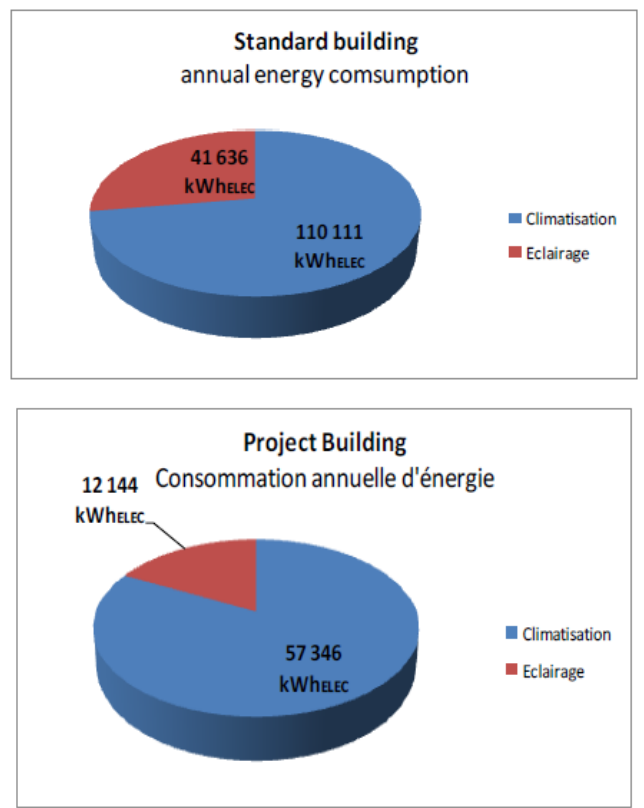

Saving energy- $54 \%$ 
Over a period of 20 years, the building designed by the project management team will allow an economy of exploitation of $€ 326529$, or an average of $€ 16326$ / year. Such building designed by the project management team will enable a saving of 82257 $\mathrm{kWh}$ of electricity / year.

\section{CONCLUSION}

Those who have adopted BIM continue to tell us about the real benefits it delivers. For the design team, there are clear benefits of collaboration, visualisation, coordination and information retrieval. This readily translates into increased cost efficiencies and profitability. The use and sophistication of BIM will continue to grow as more of the benefits of the technology have become evident. The number of buildings designed using the technology and the number of BIM users has grown dramatically over the past few years, and this trend is expected to continue. The benefits of BIM adoption depend on all parties being able to engage and collaborate in a well-informed way. In the BIM world all participants depend on each other to succeed. There may be a lot of focus on technology, but BIM is also about people and processes. People need to understand the opportunities offered by technology and make choices about how to use it.

\section{REFERENCES}

[1] Klein, S. A., Beckman, W., Mitchell, J. W., Duffie, A. J., Duffie, N. A., Freeman, T. L., Mitchell, J. C., Braun, J. E., Evans, B. L., Kummer, J. P., Urban, R. E., Fiksel, A., Thornton, J., Blair, N. J.,Williams, P. M., Bradley, D. E., McDoweel, T. P. \& Kummert, M. 2004. TRNSYS 160- A TRaNsient SYstem Simulation program, User Manual, adison, Solar Energy Laboratory, University of isconsinMadison.
[2] Laine, T., et al., 2010. Energy and Thermal Performance Management Through Utilisation of Building Information Models NBDM, Neutral Building Data Model, http://nbdm.org/

[3] Nytsch-Geusen, C. et al., 2003. Integration of CAAD, Thermal Building Simulation and CFD by using IFC Data Exchange Format, Eigth International IBPSA Conference, Eindhoven, Netherland.

[4] Bazjanac, V. 2008. IFC BIM-based methodology for semi-automated building energy performance simulation. In L. Rischmoller (ed.), CIB W78, Proc. 25th conf.

[5] Ford, S., Aouad, G., Kirkham, J., Brandon, P., Brown, F., Child, T., Cooper, G., Oxman, R., Young, B., 1995. An information engineering approach to modelling building design, Automation in Construction 4(1), pp. 5-15.

[6] Sacks, R., Eastman, C.M., Lee, G., 2004. Parametric 3D modeling in building construction with examples from precast concrete, Automation in Construction 13(3), pp. 291-312.

[7] Migilinskas, D., Ustinovichius, L., 2006. Computer-aided modelling, evaluation and management of construction project according PLM concept,Lecture Notes in Computer Science 4101, pp. 242-250.

[8] Eastman, C., Teicholz, P., Sacks, R., Listo, K., 2008. BIM handbook: A guide to building information modeling for owners, managers, designers, engineers, and contractors. Hoboken (New Jersey): Wiley, p. 490. 